\title{
Two age of acquisition effects in the reading of Japanese Kanji
}

\author{
Makiko Yamazaki, Andrew W. Ellis*, Catriona M. Morrison $\dagger$ \\ and Matthew A. Lambon Ralph \\ Department of Psychology, University of York, Heslington, York YO1 5DD, UK
}

\begin{abstract}
Native speakers of Japanese were shown single-character Kanji words which they read aloud as quickly as possible. Simultaneous multiple regression was used to investigate which of a set of nine variables predicted reading speed. Two factors exerted strong independent effects upon reading speed-the age at which the words enter a Japanese child's spoken vocabulary and the age at which Japanese children learn the characters that are used to write those words. Of three measures of word frequency, only rated familiarity made a significant independent contribution. There were no significant effects of word imageability, the number of alternative pronunciations of a Kanji character, the visual complexity of a character, or the length of the spoken word. We suggest that the quality of lexical representations is affected by the age at which they are learned, and that the effects of age of spoken and written acquisition reflect the influence of those variables upon the speech output lexicon and the visual input lexicon respectively.
\end{abstract}

When instructed to read single words aloud as fast and as accurately as possible, skilled readers of English consistently pronounce some words faster than others. Exploration of the factors which make some words easier or harder to read aloud than others has formed a central part of the study of word recognition, and the discoveries place powerful constraints upon theories and models of reading (e.g. Monsell, 1991; Norris, 1994; Seidenberg \& McClelland, 1989).

One of the many factors that have been implicated as determinants of reading speed is the age at which words are learned. The suggestion here is that, all other things being equal, words learned early in life can be read aloud faster than words learned later in life. For example, Coltheart, Laxon \& Keating (1988) compared reading latencies for sets of early and late acquired words that were matched on frequency of occurrence in written English and on their rated imageability (a scale which places words denoting very concrete objects at one end and words denoting very abstract concepts at the other): The mean naming latencies for the early acquired words were significantly shorter than those for the late acquired words. In contrast, there was no significant difference between the latencies for high imageability (concrete) and low imageability (abstract) words matched on frequency and age of acquisition.

* Requests for reprints.

† Now at the School of Psychology, Cardiff University, Wales. 
Several other studies have reported effects of age of acquisition on word reading speed (Brown \& Watson, 1987; Gilhooly \& Logie, 1981; Morrison \& Ellis, 1995; Rubin, 1980). The measure of age of acquisition used in these studies is based on adult estimates of the age at which children first learn different words. There is a considerable body of evidence to indicate that these ratings are both valid and reliable (Morrison \& Ellis, 1995). For example, Gilhooly \& Gilhooly (1980) obtained a correlation of .93 between the estimated age of acquisition of a set of 53 words and the norms of the Chrichton and Mill Hill Vocabulary Scales (Raven, 1954). Recent work in our own laboratory has produced a correlation of .75 between adults' estimates of the age of acquisition of 265 object names and an objective measure obtained by asking 300 children aged 2:6 to 10:11 to name the same objects (Morrison, Ellis \& Chappell, in press). A regression analysis found objective age of acquisition to be the single best predictor of rated age of acquisition.

Age of acquisition effects have also been reported in studies of the speed at which pictures of objects can be named; indeed, age of acquisition effects were observed in picture naming before they were observed in reading (Carroll \& White, 1973; Gilhooly \& Gilhooly, 1979; Morrison, Ellis \& Quinlan, 1992). Given their presence in both reading and picture naming, theorists have been tempted to assign a common locus to the effects seen in both tasks. Using the framework of Morton's (1979) logogen model, Gilhooly \& Watson (1981) suggested that the thresholds of the output logogens from which spoken word forms are retrieved in both reading and naming may be determined by age of acquisition, with earlier acquired words having lower thresholds than later acquired words, and therefore being more accessible. Brown \& Watson (1987) offered a variant of the same notion. They suggested that the phonological (speech-based) representations of early acquired words may be stored as whole units whereas the representations of later acquired words may be more fragmented. The need to assemble the phonological form of a late acquired word, but not an early acquired word, could account for the additional time needed to produce the former in reading and naming tasks.

Such proposals are not without their problems. If age of acquisition is integral to the organization of the lexical store that is used to produce spoken words (the speech output lexicon), why is it not similarly integral to the organization of the lexical store that is used to recognize written words (the visual input lexicon)? It would surely be curious if age of acquisition was central to the functioning of the one lexicon but not the other. We wish to suggest here that age of acquisition is indeed central to the workings of both the speech output lexicon and the visual input lexicon, and that under the right circumstances effects attributable to both loci can be observed.

An experimenter wishing to observe effects of both spoken and written age of acquisition would need to know the age at which words enter children's spoken vocabulary and the age at which children learn to read those words. While we would not want to rule out the possibility of obtaining separate measures of spoken and written age of acquisition for English readers, we suspect that there might be quite a high degree of variability in the age at which English children first encounter particular words in written form, depending on such things as the reading scheme(s) used to teach the child to read. It is certainly easier to distinguish ages of spoken and written acquisition in the language used in the present study - Japanese- 
because the Japanese Ministry of Education decrees the precise age at which school children should learn the different Japanese characters. That is one reason for using Japanese in the present study; another is the fact that all the published accounts of age of acquisition effects have used English speakers. If our models of naming and reading are to have universal application, then it is important that we should gather data from as wide a range of languages and scripts as possible. A realization of this fact has been reflected in a recent growth of studies of reading in non-English languages such as Japanese (e.g. Kinoshita \& Saito, 1992; Morton, Sasanuma, Patterson \& Sakanuma, 1992; Shimamura, 1987; Wydell, Patterson \& Humphreys, 1993; Wydell, Butterworth \& Patterson, 1995).

In order to introduce the present experiment we will need to say a little about the Japanese language and its writing system. For those wishing to know more, fuller descriptions can be found in Morton \& Sasanuma (1984), Sampson (1985) and Shibatani (1990). Simplifying considerably, we can say that Japanese has a mixed writing system which uses both logographic (whole word) characters called Kanji and syllabic characters called Kana. The Kanji characters are used to represent most nouns, verbs and adjectives while the syllabic Kana are used for grammatical morphemes and for words adopted from other languages, for which no Kanji character exists.

Kanji characters were originally borrowed from the Chinese language. Like Chinese characters, they are logographic; that is, the whole character or combination of characters represents a word in the spoken language. Altogether there are nearly 50000 Kanji characters, and it is reckoned that at least 3000 of these must be known in order to read everyday newspapers and magazines (Morton \& Sasanuma, 1984). Many Kanji words are compounds, made up of combinations of more than one character, but there are a substantial number of single character Kanji words.

Japanese children enter formal education at the age of seven years. They spend six years at elementary school before transferring to junior high school (ages 13 to 15). At least 90 per cent of children then spend another three years at senior high school. In 1981 the Japanese Ministry of Education published a list of 1945 Kanji characters called 'joyo-kanji' (commonly used Kanji) which all Japanese children should learn during their years of compulsory education (7-15 years). Furthermore, the Ministry decreed which characters were to be learned in which year of schooling in a list called 'gakunen-haitouhyou'. Textbooks for each school year introduce the predetermined Kanji characters in easy sentences. Children are required to memorize each one and to practise writing it. Regular tests are given to ensure that the characters are learned.

In the present study, native speakers of Japanese read Kanji nouns as quickly as possible. The stimuli were all single character Kanji. An aspect of Japanese orthography that we have not already mentioned, but need to now, is the fact that most Kanji characters have (at least) two pronunciations or 'readings'. The 'Kun' reading is the pronunciation of the Japanese word which the Kanji character was originally borrowed to represent. For example, the Chinese character meaning parent was adopted for the Japanese word for parent, 'oya'. This is the Kun reading given to the character when it occurs in isolation and when it occurs in compounds such as 'chichioya' (father) and 'hahaoya' (mother). But when Chinese characters were borrowed, the Japanese also took over some of the corresponding Chinese 
pronunciations. 'On' readings of Kanji characters are derived from spoken Chinese, though they are now firmly established as part of the Japanese language. For example, the character whose Kun reading is 'oya' also has the On reading 'shin' which occurs in words like 'shinrui' (relatives) and 'ryoushin' (parents). The Kun reading of a single Kanji character always represents a whole word whereas the On reading usually forms part of a word represented by two or more characters (as in the examples 'shinrui' and 'ryoushin'). The object of investigation in the present study was the time required to read aloud single character Kanji in their Kun readings. As we shall see, although this sounds complicated to readers unused to Japanese, the participants in the experiment responded rapidly to the characters and made very few mispronunciation errors.

In common with most other studies of age of acquisition effects, we employed multiple regression techniques to discover which of a set of predictor variables influenced naming speed for the single character Kanji. Our measure of the age at which the words enter a child's spoken vocabulary was based on adult estimates, while age of written acquisition was taken from the gakunen-haitouhyou list. Three measures of word frequency (or familiarity) were employed in acknowledgement of the widespread belief that word frequency is another of the factors which influence reading speed (see Monsell, 1991, for a review). Word frequency and age of acquisition are naturally correlated in that more common words tend to be learned earlier than less common words. Hence care has to be taken to tease apart their relative contributions to word recognition. We note in passing that most of the studies reporting frequency effects in English have failed to control for age of acquisition, and that studies which bave taken the care to separate them have often found it difficult to identify an independent effect of word frequency on reading speed once age of acquisition is controlled (see Morrison \& Ellis, 1995, for further elaboration of this point).

The words used were also rated for imageability, despite the fact that studies of English reading have found either no effect of imageability on reading speed (Brown \& Watson, 1987; Coltheart et al., 1988; Gilhooly \& Logie, 1981; Richardson, 1976; Rubin, 1980) or an effect restricted to a small subset of words (e.g. words of low frequency with irregular spellings; Strain, Patterson \& Seidenberg, 1995).

Although the Kun reading is the natural pronunciation of a single character Kanji word, many have alternative On readings (or even less frequent Kun readings). Wydell et al. (1995, Expt 6) compared the speed of reading single character Kanji words that have only one On pronunciation in addition to their Kun pronunciation with the speed of reading words that have two additional On readings. There was no significant effect of the number of alternative pronunciations of a character. Nevertheless, the number of alternative readings of each character (varying from 0 to 5) was included as a predictor variable in the present study. Word length, measured as the number of 'mora' (roughly, syllable) units in a word, was included as another predictor variable, as was the visual complexity of the characters, measured in terms of the number of strokes required to write each character. 


\section{Method}

\section{Participants}

Participants were 26 native speakers of Japanese, aged 18 to 24 years. All had normal or corrected-tonormal vision.

\section{Materials}

The stimuli were 150 single character Kanji words which appeared in the gakunen-haitouhyou list and for which ratings on various dimensions had been obtained by Wydell (1991). Figure 1 gives examples of the characters used. Words beginning with ' $s h$ ', ' $s$ ' or ' $h$ ' were excluded to optimize activation of the voice key. Ratings were obtained for each word/character on nine predictor variables. All ratings related to the dominant Kun reading of each character and were obtained from different individuals from those who participated in the experiment.

$\begin{array}{ccccc}\begin{array}{c}\text { Kanji } \\ \text { character }\end{array} & \begin{array}{c}\text { Pronunci } \\ \text {-ation }\end{array} & \text { Meaning } & \begin{array}{c}\text { Spoken } \\ \text { AoA }\end{array} & \begin{array}{c}\text { Written } \\ \text { AoA }\end{array} \\ \text { 足 } & \text { ashi } & \text { foot } & 1.40 & 1 \\ \text { 顔 } & \text { kao } & \text { face } & 1.90 & 2 \\ \text { 湖 } & \text { mizuumi } & \text { lake } & 2.35 & 2 \\ \text { 傷 } & \text { kizu } & \text { injury } & 3.25 & 6 \\ \text { 旅 } & \text { tabi } & \text { travel } & 3.95 & 3 \\ \text { 横 } & \text { yoko } & \text { side } & 4.00 & 3 \\ \text { 恋 } & \text { koi } & \text { love } & 4.70 & 8\end{array}$

Figure 1. Examples of the single character Kanji characters used in the study of reading speed.

$41 N$

Age of spoken acquisition was rated for each word by 21 native speakers of Japanese who were participating in an English language course at the University of York. Following the standard procedure used for gathering age of acquisition norms in English (e.g. Gilhooly \& Logie, 1980), the raters used a seven-point scale to indicate the age at which they believe Japanese children learn the spoken word denoted by the Kun reading of each of the $150 \mathrm{Kanji}$. The scale runs from 1 = words learned before the age of two, through $2=$ words learned between two and three years of age, to $7=$ words learned at or beyond the age of 13 . The instructions emphasized the need to estimate the age at which words enter children's spoken vocabulary, not the age at which children learn the corresponding Kanji character. Cronbach's alpha indicated a very high degree of internal consistency among raters in the ratings given to the different items $(\alpha=.99)$. The mean estimated age of spoken acquisition of the stimuli was 2.68 on the seven-point scale (range 1.40 to 4.79 ).

Age of written acquisition was taken from the gakunen-haitouhyou list published by the Japanese Ministry of Education. Kanji characters learned in the first year of elementary school (age seven) were assigned a value of 1 , those learned in second year a value of 2 , and so on up to the sixth year. Kanji learned 
during the junior high school years (ages 13 to 15 ) were given a value of 8 . We should acknowledge at this point that the gakunen-haitouhyou list does not specify which pronunciation of a character should be learned when that character is first introduced, but Kun readings are typically learned first, with On readings (which usually occur as parts of compound Kanji) being learned later (Nomura, 1979). The mean age of written acquisition of the stimuli was 3.85 on the eight-point scale (range 1 to 8 ).

Rated Kanji word frequency values were taken from Wydell (1991) who had 12 Japanese participants rate 2357 words on a seven-point scale for how often they see the Kanji character for each word. The mean rated word frequency of the stimuli was 3.55 (range 2.17 to 5.83 ).

Character frequency was taken from 'gendai shinbun no Kanji' (Kanji characters used in newspapers) published by the National Language Research Institute of Japan in 1976. A total of 3212 Kanji characters were sampled from three major national newspapers for the 12 months of 1966 and the occurrence of each character was counted. Character frequency is different from word frequency in that it includes each occurrence of a character, whether as a single character word or as part of a compound with other characters. This measure was logged to reduce skew. The mean log character frequency of the stimuli was 2.22 (range 0 to 3.86 ).

Familiarity ratings were also taken from Wydell (1991). In this instance words were rated on a sevenpoint scale according to how familiar the concepts denoted by the character are to Japanese speakers. Instructions emphasized that participants were to rate the familiarity of the meanings or concepts rather than the frequency with which they used or encountered the words. The mean familiarity of the stimuli was 4.73 (range 2.64 to 6.27 ).

Imageability ratings were again taken from Wydell (1991) who had words rated on a seven-point scale according to their capacity to arouse mental images of things or events. The mean imageability of the stimuli was 6.34 (range 3.80 to 7.00 ). The high mean indicates that Kun readings of single character Kanji tend to denote concrete nouns while abstract nouns tend to be represented by compound Kanji (Wydell, personal communication, 1995).

Number of alternative pronunciations was a measure of the number of alternative On or Kun readings of each character. The mean number of alternative pronunciations of the stimuli was 1.27 (range 0 to 5 ).

Spoken word length was measured as the number of 'mora' units in the pronunciation of the word. A mora is a speech unit in Japanese similar to the syllable in English-it may be a consonant-vowel combination, a vowel alone, or a nasal sound (Shibatani, 1990). The mean length of the stimuli was 2.20 morae (range 1 to 4 ).

The visual complexity of each Kanji character was measured as the number of strokes required to write the character, taken from the Sanseido Kanji Dictionary (Nagasawa, 1990). The mean complexity of the stimuli was 9.09 strokes (range 2 to 19 ).

\section{Procedure}

The experiment was run in Japan on a Macintosh Powerbook 100 computer using Psychlab software (Bub \& Gum, 1990). The Kanji characters were generated using the Macintosh software SWEETJAM. Reaction times were recorded by the computer through a high sensitivity microphone connected to a voice key.

The $150 \mathrm{Kanji}$ were divided into three blocks of 50 . The order of presentation of the three blocks was the same for all participants, but the order of stimuli within the blocks was randomized for each participant. Each block of 50 trials was initiated by a warm-up trial. Ten practice items were presented at the beginning of the experiment to familiarize individuals with the experiment and procedure.

Each trial began with a fixation dot presented for $350 \mathrm{~ms}$. A target character then appeared on the screen where it remained for $3000 \mathrm{~ms}$ or until a response had been made. There was an interval of 
$3000 \mathrm{~ms}$ between the production of a naming response and the start of the next trial. Participants were instructed to read each character as quickly as possible and to give a Kun reading for each character.

\section{Results}

Despite the fact that many of the stimulus characters could, in principle, be given alternative readings, the high familiarity of the desired Kun readings compared with the (mostly On) alternatives meant that misreadings only accounted for only three trials out of 3900 . Mispronunciations, hesitations and misfirings of the voice key accounted for an additional 1.7 per cent of trials. Three items ('chichi', 'tsuchi' and 'chikara') were responsible for most of the voice key misses and were removed from the analysis. The mean reading speed ${ }^{1}$ of the 147 remaining Kanji characters was $629 \mathrm{~ms}$, with a range of 537 to $1117 \mathrm{~ms}$. These latencies are comparable to those observed in studies of reading speed in English.

Table 1 shows the intercorrelations of the predictor variables with each other and with the mean naming latency for the 147 Kanji characters. Reading speed has its highest raw correlations with the two age-of-acquisition measures, but also correlated significantly with rated Kanji word frequency, familiarity and number of alternative pronunciations. Such raw correlations must be viewed with caution, however, when the predictor variables are themselves intercorrelated, as is the situation here. The correlations of reading speed with log character frequency, imageability, spoken word length and visual complexity were all non-significant.

Imageability was excluded from the regression analyses because of its extremely low correlation with reading speed. ${ }^{2}$ Rated word frequency, character frequency and familiarity might be thought of as different measures of the same thing (word frequency) and were not therefore included together in the same regression analysis. Accordingly, three separate analyses were carried out, one for each of these alternative frequency/familiarity measures with the remaining five predictor variables.

Table 2 shows the results of the three simultaneous multiple regression analyses. All three equations were highly significant, and the three combinations of variables accounted for similar proportions of the overall variance. Age of written acquisition and age of spoken acquisition made highly significant independent contributions in each analysis. Figure 2 shows the simple regressions of naming latency against the two age-of-acquisition measures. The graphs show a simple linear relationship between age of acquisition and reading speed, with a one-year difference in age of spoken and written acquisition corresponding to differences in reading speed of roughly $44 \mathrm{~ms}$ and $16 \mathrm{~ms}$ respectively.

Of the three frequency/familiarity measures, familiarity made a significant independent contribution to predicting naming speed when included with the two age-of-acquisition measures, number of alternative pronunciations, length and visual

1 Reading speed here refers to untransformed naming RT.

2 Imageability is biased towards the concrete end of the scale because single character Kanji tend to represent concrete words. It is also skewed (mean 6.34 on a scale of 1 to 7 with a minimum of 3.80 and a maximum of 7.00 ). However, the pattern of correlations remained largely unchanged when a log (7-imag) transform was used to reduce skew. In this case the correlation with reading speed was just .02 . 
Makiko Yamazaki et al.

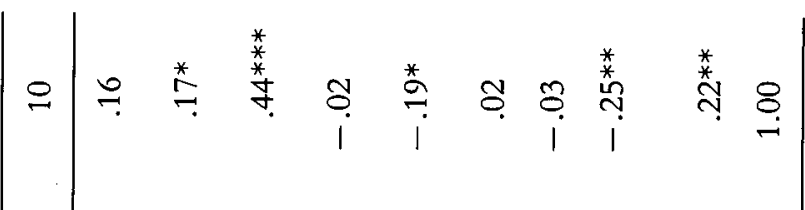

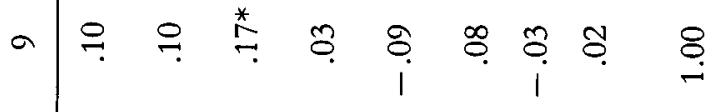

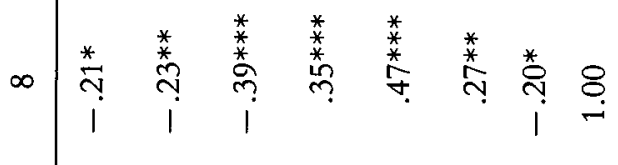

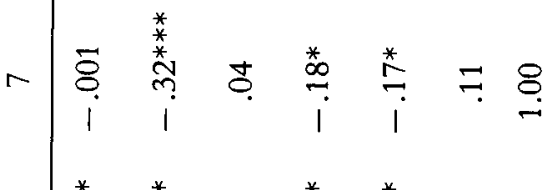

$$
\begin{aligned}
& \text { | }
\end{aligned}
$$

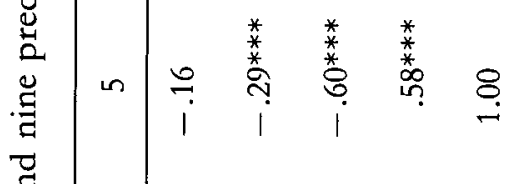

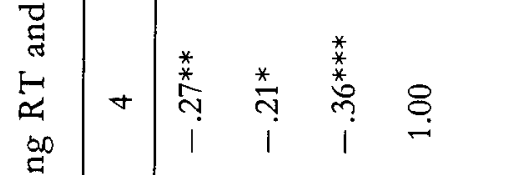

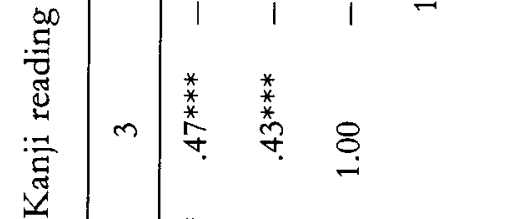

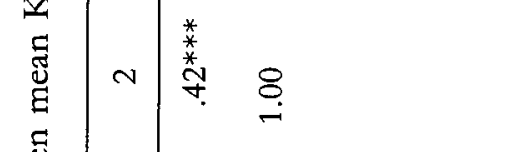

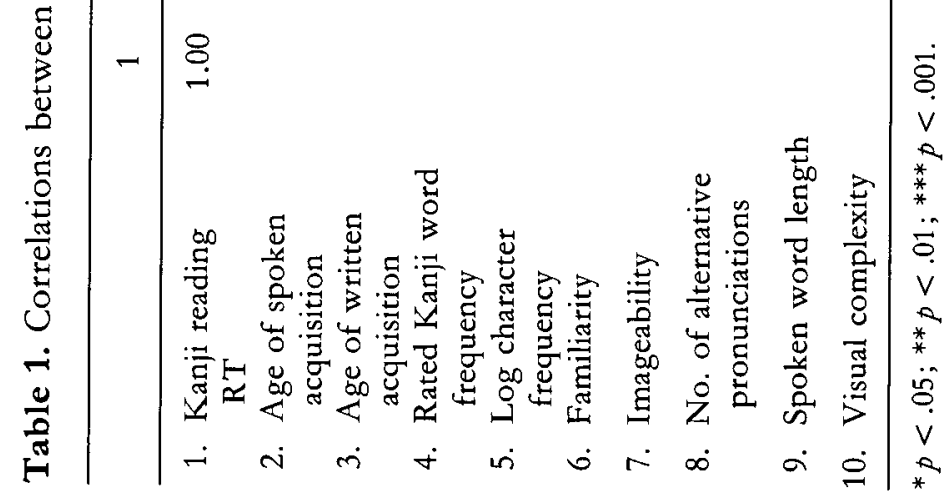


Age of acquisition effects

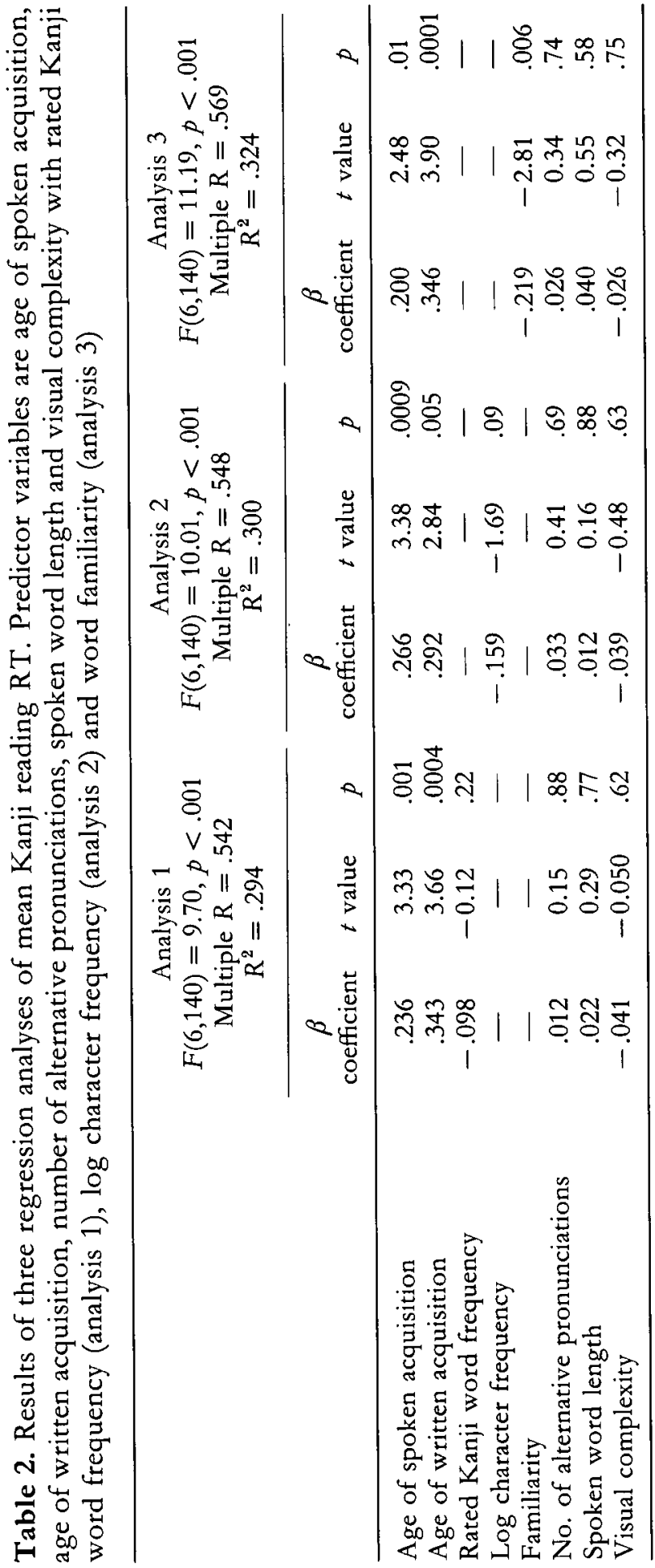




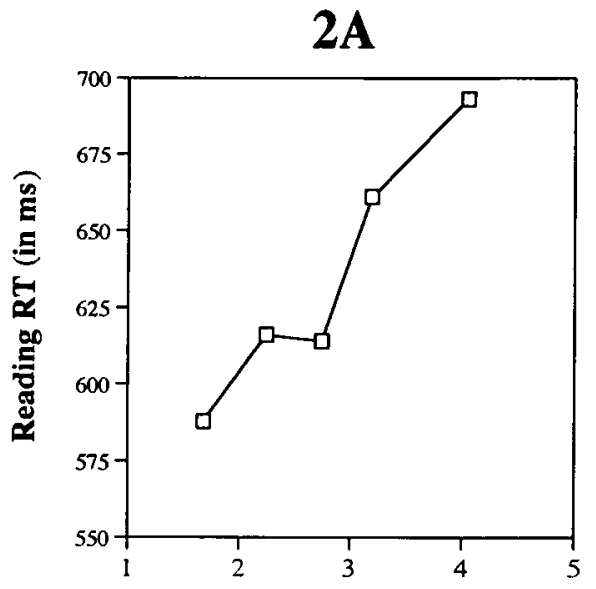

Spoken AoA

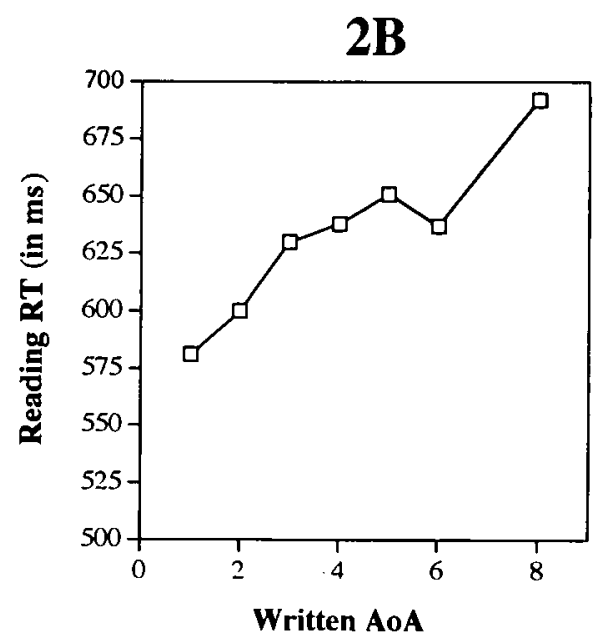

Figure 2. The simple regression of age of spoken acquisition (Fig. 2A) and age of written acquisition (Fig. 2B) on Kanji word reading time.

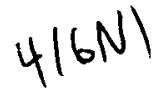

complexity. When log character frequency replaced familiarity, its independent contribution approached significance $(p=.09)$, but when rated Kanji word frequency was used as the frequency/familiarity measure its contribution was a long way from being significant $(p=.22)$. There was no significant contribution in any of the analyses from number of alternative pronunciations, word length or visual complexity.

\section{Discussion}

Two factors clearly influence the speed at which single character Kanji can be read aloud - the age at which the spoken word represented by the character is learned, and the age at which the character itself is learned. There is some evidence for a contribution of familiarity or frequency, but no indication of any effect of the visual complexity of a character, the imageability of the meaning represented by a character, the number of alternative pronunciations it can receive, or the length of the spoken word to which it corresponds.

The lack of an effect of imageability must be interpreted with caution given the restricted range of imageabilities in the sample of words used. We note, however, that previous regression analyses of reading speeds in English, using a wider range of imageability values, have also failed to find a significant independent contribution of imageability (Brown \& Watson, 1987; Gilhooly \& Logie, 1981; Richardson, 1976; Rubin, 1980), as did Coltheart et al. (1988) in a factorial study.

There is no obvious counterpart in English of the visual complexity of a Kanji character, measured as the number of strokes required to write it. There was no detectable effect of complexity in the present study, though it might be argued that we are sampling only one end of the complexity spectrum because compound Kanji are more visually complex than single character Kanji. 
There was no effect in the present study of the number of alternative pronunciations of a Kanji character. Wydell et al. (1995) also found no effect of this factor on Kanji reading speed. Barry, Morrison \& Ellis (in press) measured naming speeds in English for 260 object pictures taken from the Snodgrass \& Vanderwart (1980) set. One of the factors which affected naming speed was the number of alternative names that speakers give to a picture. Thus, the fact that the same picture could be called a 'sofa', a 'settee' or a 'couch' seemed to retard the process of selecting and producing any one of those names. This effect was also reported by Vitkovitch \& Tyrell (1995). The fact that the number of alternative names appears to affect object naming but not Kanji reading may be pointing at some fundamental difference in the processing of pictures and Kanji characters. The latter are part of the writing system and bear very little pictorial resemblance to the concepts they represent. Whereas the activation of semantic representations appears to be a necessary stage in picture naming (Riddoch \& Humphreys, 1987), word reading (as we have noted above) is believed not to involve semantics to any great degree. One possibility is that the effect of number of alternative names in picture naming arises at the point where semantic representations are used to activate the corresponding phonological word forms, a process which takes longer when there is more than one plausible candidate (as in the sofa/couch/settee example) and a choice must be made between them. This process, and hence this effect, will be avoided when a written word form, whether in English or in Japanese, directly activates its corresponding phonology (Wydell et al., 1993).

We noted in the introduction that there is an ongoing debate about the extent to which word reading speed in English is affected by word frequency. Most of the studies of 'frequency' effects in English have confounded frequency with age of acquisition (see Morrison \& Ellis, 1995, Table 1), and when the two have been disconfounded the evidence for an independent contribution of frequency is surprisingly weak (Brown \& Watson, 1987; Gilhooly \& Logie, 1981; Morrison \& Ellis, 1995). In the present study, a subjective frequency rating derived from estimates made by Japanese adults of the frequency with which they encounter different Kanji characters showed no indication of making an independent contribution to predicting naming speed. The independent contribution of an objective character frequency count taken from Japanese newspapers was, at best, of borderline significance.

We have already noted one problem with the character frequency count, which is that it conflates occurrences of a character when it occurs as a single character Kanji with occurrences as part of a compound. Morton et al. (1992) studied the effects of repeating Kanji characters on the exposure duration required to correctly identify them when presented very briefly in a tachistoscope. Repetition had a significant effect for compound but not single character Kanji. Furthermore, there was no priming observed between recognizing single characters and recognizing compounds which contain those characters, or between recognizing compounds and recognizing single characters that had formed part of the compounds. On the basis of this pattern of results, Morton et al. (1992) concluded that the representations involved in recognizing compound characters are different from those involved in recognizing any single characters that may be contained within the compounds. If that is so, then 
frequency counts which add the frequencies of occurrence of characters in compounds to the frequencies of occurrence of those same characters appearing as single Kanji characters will lack psychological relevance and application. An objective count of the simple frequencies of different single character Kanji would then be more germane to deciding whether or not character frequency affects the recognition and reading of Kanji.

The one 'frequency' count which exerted a significant independent effect upon reading speed was Japanese adults' ratings of familiarity. Wydell et al. (1995) found similar effects of familiarity on the reading speeds of both single-character and compound Kanji words. It may be that rated familiarity is just a better measure of word frequency than the available objective counts (cf. Connine, Mullenix, Shernoff \& Yelen, 1990; Gernsbacher, 1984): we would not want to exclude the possibility that the familiarity effect found in the present study and that of Wydell et al. (1995) is indeed indicating a role for frequency in Kanji naming over and above the effects of age of acquisition. We note, though, that Wydell et al. (1995) did not control for age of acquisition in their study. Table 1 shows that rated familiarity correlates significantly with both age of spoken acquisition and age of written acquisition. Word sets selected for being high or low in familiarity will therefore tend to be of early and late age of acquisition respectively.

An alternative possibility ${ }^{3}$ is that concept familiarity is a semantic variable, and that a familiarity effect on Kanji reading is arising as a result of an involvement of semantic representations in the process of translating Kanji characters into their pronunciations. Theoretical models of reading propose that the translation of print to sound on a whole word basis may be semantically mediated, or may bypass semantics (see Seidenberg \& McClelland, 1985; Strain et al., 1995). Hirsch \& Funnell (1995) found that concept familiarity was associated with semantic deficits and age of acquisition with naming deficits in a study of two patients with progressive focal dementia. It seems quite possible, then, that the effect of familiarity could reflect a contribution of the lexical-semantic route in Kanji reading. If that is the case, then effects of concept familiarity may be a better index of semantic involvement in normal reading than effects of imageability.

Which leaves the age-of-acquisition effects. We would begin by observing that ours is the first demonstration of age-of-acquisition effects in a language other than English. Their presence encourages us in the belief that age-of-acquisition effects are telling us something fundamental about the organization of the processing systems that are responsible for recognizing and producing words. Our regression analyses reveal two separate and independent age-of-acquisition effects-one reflecting the age at which words are acquired in speaking and the other reflecting the age at which they are learned in reading. As Hulme, Quinlan, Bolt \& Snowling (1995) observe, theoretical models of reading have tended to ignore the fact that most words are learned in spoken form before they are encountered in written form. Theoretical models of reading should accommodate the fact that the speech output lexicon is in place and organized well before the visual input lexicon begins to be created.

Morrison (1993) proposed that age of acquisition effects could be modelled if

${ }^{3}$ We thank Elaine Funnell for pointing out this alternative interpretation of a familiarity effect. 
lexical stores are conceived of as self-organizing networks. As these networks are trained, they develop their own structure which is designed to maximize their ability to discriminate the different patterns they are required to learn. Similar patterns cluster at units in the same area of the network while dissimilar patterns are topographically distant (Kohonen, 1984, 1990). Morrison (1993) attempted to simulate age of acquisition effects by introducing different patterns at different points of the training of self-organizing networks. She showed that, under certain circumstances at least, self-organizing networks distribute early learned patterns across many of the available cells. Patterns introduced later in the training then have to be 'squeezed in' around the early acquired ones. Even after substantial amounts of further training, the early acquired patterns remain distributed over more cells. This may make them easier to access and also more robust to the effects of damage to the network (cf. Hirsh \& Ellis, 1994; Hirsh \& Funnell, 1995).

We propose that the effect of age of spoken acquisition reflects the contribution of the speech output lexicon to Kanji reading, and that the age of written acquisition effect reflects the contribution of the visual input lexicon. If both lexicons are thought of as self-organizing networks, then representations in the speech output lexicon will be influenced by the age at which different spoken words are acquired (or the order in which they are acquired, since it is the order with which patterns are learned rather than the age of the individual who possesses the network that we think important). Similarly, representations in the visual input lexicon will be influenced by the age or order at which different written words are acquired. One prediction arising from this view is that reading speed should be sensitive to both age of acquisition effects while object naming speed should only be sensitive to age of spoken acquisition.

\section{Acknowledgements}

Catriona Morrison was supported by a grant from the Medical Research Council and Matthew Lambon Ralph by a studentship from the Engineering and Physical Sciences Research Council. We thank Taeko Wydell for advice on the design of the experiment, for making her ratings available to us, and for comments on an earlier version of the paper. We also thank Elaine Funnell and an anonymous referee for helpful comments.

\section{References}

Barry, C., Morrison, C. M. \& Ellis, A. W. (in press). Naming the Snodgrass and Vanderwart pictures: Effects of age of acquisition, frequency and name agreement. Quarterly Journal of Experimental Psychology.

Brown, G. D. A. \& Watson, F. L. (1987). First in, first out: Word learning age and spoken word frequency as predictors of word familiarity and word naming latency. Memory and Cognition, 15, 208-216.

Bub, D. \& Gum, T. (1990). Psychlab (v. 0.85). Montreal.

Carroll, J. B. \& White, M. N. (1973). Word frequency and age-of-acquisition as determiners of picturenaming latency. Quarterly Journal of Experimental Psychology, 25, 85-95.

Coltheart, V., Laxon, V. J. \& Keating, C. (1988). Effects of word imageability and age of acquisition on children's reading. British Journal of Psychology, 79, 1-12.

Connine, C. M., Mullenix, J., Shernoff, E. \& Yelen, J. (1990). Word familiarity and frequency in visual and auditory word recognition. Journal of Experimental Psychology: Learning, Memory and Cognition, 16, 1084-1096. 
Gernsbacher, M. A. (1984). Resolving 20 years of inconsistent interactions between lexical familiarity and orthography, concreteness and polysemy. Journal of Experimental Psychology: General, 113, 256-281.

Gilhooly, K. J. \& Gilhooly, M. L. (1979). Age-of-acquisition effects in lexical and episodic memory tasks. Memory and Cognition, 7, 214-223.

Gilhooly, K. J. \& Gilhooly, M. L. M. (1980). The validity of age-of-acquisition ratings. British Journal of Psychology, 71, 105-110.

Gilhooly, K. J. \& Logie, R. H. (1980). Methods \& designs: Age of acquisition, imagery, concreteness, familiarity, and ambiguity measures for 1,944 words. Behaviour Research Methods and Instrumentation, 12, $395-427$.

Gilhooly, K. J. \& Logie, R. H. (1981). Word age-of-acquisition, reading latencies and auditory recognition. Current Psychological Research, 1, 251-262.

Gilhooly, K. J. \& Watson, F. L. (1981). Word age-of-acquisition effects: A review. Current Psychological Research, 1, 269-286.

Hirsh, K.W. \& Ellis, A. W. (1994). Age of acquisition and aphasia: A case study. Cognitive Neuropsychology, 11, 435-458.

Hirsh, K. W. \& Funnell, E. (1995). Those old, familiar things: Age of acquisition, familiarity and lexical access in progressive aphasia. Journal of Neurolinguistics, 9, 23-32.

Hulme, C., Quinlan, P., Bolt, G. \& Snowling, M. (1995). Building phonological knowledge into a connectionist model of the development of word naming. Language and Cognitive Processes, 10, 387-391.

Kinoshita, A. \& Saito, H. (1992). Effects of concurrent articulation on reading Japanese Kanji and Kana words. Quarterly Journal of Experimental Psychology, 44A, 455-474.

Kohonen, T. (1984). Self-Organization and Associative Memory. Berlin: Springer-Verlag.

Kohonen, T. (1990). The self-organising map. Proceedings of the IEEE, 78, 1464-1480.

Monsell, S. (1991). The nature and locus of word frequency effects in reading. In D. Besner \& G. W. Humphreys (Eds), Basic Processes in Reading: Visual Word Recognition, pp. 148-197. Hillsdale, NJ: Erlbaum.

Morrison, C. M. (1993). Loci and roles of word age of acquisition and word frequency in lexical processing. Unpublished DPhil thesis, University of York, York, UK.

Morrison, C. M. \& Ellis, A. W. (1995). The roles of word frequency and age of acquisition in word naming and lexical decision. Journal of Experimental Psychology: Learning, Memory and Cognition, 21, 116-133.

Morrison, C. M., Ellis, A. W. \& Chappell, T. (in press). Age of acquisition norms for a large set of object names and their relation to adult estimates and other variables. Quarterly Journal of Experimental Psychology.

Morrison, C. M., Ellis, A. W. \& Quinlan, P. T. (1992). Age of acquisition, not word frequency, affects object naming, not object recognition. Memory and Cognition, 20, 705-714.

Morton, J. (1979). Facilitation in word recognition: Experiments causing change in the logogen model. In P. A. Kolers, M. Wrolstad \& H. Bouma (Eds), Processing of Visible Language, vol. 1, pp. 259-268. New York: Plenum.

Morton, J. \& Sasanuma, S. (1984). Lexical access in Japanese. In L. Henderson (Ed.), Orthographies and Reading, pp. 25-42. London: Erlbaum.

Morton, J., Sasanuma, S., Patterson, K. \& Sakanuma, N. (1992). The organisation of the lexicon in Japanese: Single and compound Kanji. British Journal of Psychology, 83, 517-531.

Nagasawa, K. (1990). Sanseido's Kanji Dictionary. 4th ed. Tokyo: Sanseido.

Nomura, Y. (1979). Information processing of Chinese characters (Kanji): Retrieval processes in Chinese-style reading $(\mathrm{ON})$ and Japanese-style reading (KUN). Japanese Journal of Psychology, 50, 101-105 (in Japanese).

Norris, D. (1994). A quantitative multiple-levels model of reading aloud. Journal of Experimental Psychology: Human Perception and Performance, 20, 1212-1232.

Raven, J. C. (1954). Guide to Using the Mill Hill Vocabulary Scale with Progressive Matrices (1947), Sets A, Ab, B. London: H. K. Lewis.

Richardson, J. T. E. (1976). The effects of stimulus attributes upon latency of word recognition. British Journal of Psychology, 67, 315-325. 
Riddoch, M. J. \& Humphreys, G. W. (1987). Picture naming. In G. W. Humphreys \& M. J. Riddoch (Eds), Visual Object Processing: A Cognitive Neuropsychological Approach, pp. 107-143. London: Erlbaum.

Rubin, D. C. (1980). 51 properties of 125 words: A unit analysis of verbal behavior. Journal of Verbal Learning and Verbal Behavior, 19, 736-755.

Sampson, G. (1985). Writing Systems. London: Hutchinson.

Seidenberg, M. S. \& McClelland, J. L. (1989). A distributed, developmental model of word recognition and naming. Psychological Review, 96, 523-568.

Shibatani, M. (1990). The Languages of Japan. Cambridge: Cambridge University Press.

Shimamura, A. (1987). Word comprehension and naming: An analysis of English and Japanese orthographies. American Journal of Psychology, 100, 15-40.

Snodgrass, J. G. \& Vanderwart, M. (1980). A standardized set of 260 pictures: Norms for name agreement, image agreement, familiarity, and visual complexity. Journal of Experimental Psychology: Human Learning and Memory, 6, 174-215.

Strain, E., Patterson, K. E. \& Seidenberg, M. S. (1995). Semantic effects in single-word naming. Journal of Experimental Psychology: Learning, Memory and Cognition, 21, 1140-1154.

Vitkovitch, M. \& Tyrell, L. (1995). Sources of disagreement in object naming. Quarterly Journal of Experimental Psychology, 21, 1155-1168.

Wydell, T. N. (1991). Processes in the reading of Japanese: Comparative studies between English and Japanese orthographies. Unpublished $\mathrm{PhD}$ thesis, University of London.

Wydell, T. N., Patterson, K. E. \& Humphreys, G. W. (1993). Phonologically mediated access to meaning for Kanji: Is a rows still a rose in Japanese Kanji? Journal of Experimental Psychology: Learning, Memory and Cognition, 19, 491-514.

Wydell, T. N., Butterworth, B. \& Patterson, K. E. (1995). The inconsistency of consistency effects in reading: The case of Japanese Kanji. Journal of Experimental Psychology: Learning, Memory and Cognition, 21, 1155-1168. 
Copyright of British Journal of Psychology is the property of British Psychological Society and its content may not be copied or emailed to multiple sites or posted to a listserv without the copyright holder's express written permission. However, users may print, download, or email articles for individual use. 